greater than that found by Register and Sarett (1951) but not out of keeping with those reported by Girdwood (1951), Mollin and Ross. (1952), Heinrich (1954), Jones, Mills, and Capps (1957), and Linnell et al. (1968) in smaller series of normal subjects and by Girdwood (1951), Mollin and Ross (1952), and Heinrich (1954) in patients with pernicious anaemia. The mean value of daily urine vitamin $B_{12}$ in the nonvitamin $B_{12}$-deficient subjects was $164 \mathrm{ng}$./day, which is higher than that previously found by direct measurement but less than that calculated by Hall (1964) from kinetic studies. The significance of mean values is doubtful, however, as the distribution of daily urine vitamin $B_{12}$ values is lognormal, as is the distribution of serum vitamin $B_{12}$ levels in normal subjects (Gräsbeck 1961).

The results are of interest in relation to the proportionate losses of vitamin $\mathrm{B}_{12}$ from the body by the renal and intestinal routes. Serial whole-body measurements in normal and in vitamin $B_{12}$-deficient subjects given radioactive cobalamins orally or parenterally have shown that the daily loss of vitamin $B_{12}$ from the body is a function of the total body stores amounting to $0.1-0.2 \%$ of stores per day (Heyssel, Bozian, Darby, and Bell, 1966; Adams and Boddy, 1968; Boddy and Adams, 1968). Thus with stores of 2,000 $\mu \mathrm{g}$. the daily loss will be $2-4 \mu \mathrm{g}$.: from the results it is clear that the contribution to this total by the urine loss will be small. With a fall in body stores to say $100 \mu \mathrm{g}$. and a fall in serum vitamin $B_{12}$ level to subnormal values the total daily loss will amount to 100 to $200 \mathrm{ng}$., and the contribution to this total by the urinary loss will be proportionately greater than in normal circumstances and may then account for half of the total loss.

The correlation between the serum and urine vitamin

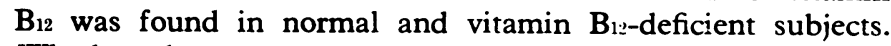
Whether the measurements are correlated in disease states accompanied by a high serum vitamin- $B_{12}$ level, such as chronic myeloid leukaemia (Beard, Pitney and Sanneman, 1954; Mollin and Ross, 1955; Miller and Sullivan, 1958), renal failure (Matthews and Beckett, 1962), or hepatic disease (Holdsworth,
Atkinson, Dossett, and Hall, 1964; Neale, Caughey, Mollin, and Booth, 1966; Rachmilewitz and Eliakim, 1968) has not been investigated, and further study of this aspect may be necessary to comprehend the problem of vitamin $\mathbf{B}_{1:}$ balance in disease states.

\section{REFERENCES}

Adams, J. F., and Boddy, K. (1968). Fournal of Laboratory and Clinical Medicine, 72, 392.

Beard, M. F., Pitney, W. R., and Sanneman, E. H. (1954). Blood, 9, 789. Boddy, K., and Adams, J. F. (1968). American fournal of Clinical Nutrition, 21, 657.

Girdwood, R. H. (195i). Edinburgh Medical fournal, 58, 309.

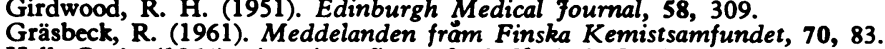
Gräsbeck, R. (1961). Meddelanden fram Finska Kemistsamfundet, 70,

Hall, C. A., and Finkler, A. E. (1962.) fournal of Laboratory and Clinical Medicine, 60, 765.

Hall, C. A., and Finkler, A. E. (1965). Fournal of Laboratory and Clinical Medicine, 65, 459 .

Heinrich, H. C. (1954). Klinische Wochenschrift, 32, 867.

Heyssel, R. M., Bozian, R. C., Darby, W. J., and Bell, M. C. (1966) American foumal of Clinical Nutrition, 18, 176.

Holdsworth, C. D., Atkinson, M., Dossett, J. A., and Hall, R. (1964) Gut, 5, 601 .

Hom, B., and Olesen, H. (1967). Scandinavian fournal of Clinical and Laboratory Investigation, 19, 269.

Hom, B., Olesen, H., and Lous, P. (1966). Fournal of Laboratory and Clinical Medicine, 68, 958.

Hutner, S. H., Bach, M. K., and Ross, G. I. M. (1956). Fournal of Protozoology, 3, 101.

Jones, P. N., Mills, E. H., and Capps, R. B. (1957). Fournal of Laboratory and Clinical Medicine, 49, 910.

Linnell, J. C., Smith, A. D. M., Smith, C. L., Wilson, J., and Matthews, D. M. (1968). British Medical fournal, 2, 215

Matthews, D. M., and Beckett, A. G. (1962). fournal of Clinical Pathology, $15,456$.

Miller, A., and Sullivan, J. F. (1958). fournal of Clinical Investigation, 37, 556.

Mollin, D. L., and Ross, G. I. M. (1955). British fournal of Haematology, 1,155 .

Mollin, D. L., and Ross, G. I. M. (1952). Fournal of Clinical Pathology, 5, 129.

Neale, G., Caughey, D. E., Mollin, D. L., and Booth, C. C. (1966). British Medical Fournal, 1, 382.

Rachmilewitz, M., and Eliakim, M. (1968). Israel fournal of Medical Science, $4,47$.

Register, U. D., and Sarett, H. P. (1951). Proceedings of the Society for Experimental Biology and Medicine, 77, 837.

\title{
Effect of Ergotamine and Ergometrine on Forearm Venous Compliance in Man
}

\author{
O. G. BROOKE, ${ }^{*}$ M.B., B.S., M.R.C.P. ; B. F. ROBINSON, $†$ M.D., M.R.C.P.
}

\begin{abstract}
ummary: The effect of ergotamine and ergometrine on the venous compliance of the forearm has been studied in normal persons. Ergotamine tartrate $(0.25 \mathrm{mg}$. intravenously) led to a fall in venous compliance amounting to $49 \%$ on average, while ergometrine maleate ( $0.25 \mathrm{mg}$. intravenously) caused a reduction of $41 \%$; these changes were statistically significant. The potent venoconstrictor action of these ergot alkaloids appears to be a major component of the circulatory response to small doses and may be important in provoking the harmful cardiovascular side-effects (such as angina and pulmonary oedema) that are sometimes observed in patients with pre-existing heart disease.
\end{abstract}

\section{Introduction}

The ergot alkaloids have been widely used in medicine and obstetrics for many years, and the risk of gangrene from excessive dosage is well recognized (Goodman and Gilman,
1965). There is, however, some risk of harmful side-effects with standard clinical doses in patients with certain cardiac abnormalities. Thus ergotamine may aggravate the symptoms of angina pectoris in patients with ischaemic heart disease (Friedman et al., 1959), while ergometrine is believed to carry some risk of precipitating pulmonary oedema if given post partum to patients with mitral stenosis (Barnes, 1965). The mechanism of these untoward effects is not clear, though possible explanations have been advanced.

In analysing the circulatory side-effects of the ergot alkaloids it is important to understand their action on the peripheral circulation. The complex effect of these drugs on the arterial system has been studied in detail (Dale, 1906; Rothlin, 1947; Bluntschli and Goetz, 1948; Barcroft et al., 1951), but their effect on the venous system has received little attention. We

\footnotetext{
* Senior House Officer.

† Senior Lecturer in Medicine.

Medical Unit, St. George's Hospital, London S.W.1.
} 
have therefore investigated the action of the two commonly used ergot alkaloids, ergotamine and ergometrine, on the venous compliance of the human forearm. The results show that both alkaloids are potent venoconstrictors in clinically used doses.

\section{Methods}

Forearm venous compliance was estimated by measuring the change in forearm volume that occurred when the local venous pressure in the forearm was varied between two arbitrary but fixed levels; the method has been described in detail elsewhere (Robinson and Wilson, 1968). In brief, a sphygmomanometer cuff on the upper arm was inflated to about 30 $\mathrm{mm}$. $\mathrm{Hg}$ and maintained at this pressure for three minutes to allow equilibration to occur. The cuff was then deflated during one minute and the change in forearm volume recorded simultaneously with the change in forearm venous pressure; forearm volume was measured by means of a mercury-inrubber strain gauge, and forearm venous pressure by means of a short length of nylon catheter introduced into the radial vein and connected to a Statham $23 \mathrm{D}$ pressure transducer. Forearm venous compliance was normally expressed as the change in volume per $100 \mathrm{ml}$. of forearm for a fall in pressure from 25 to $5 \mathrm{~mm}$. $\mathrm{Hg}$. In some patients the forearm venous pressure did not fall to $5 \mathrm{~mm} . \mathrm{Hg}$ in every study, and in these a slightly different pressure interval was used; in any one experiment, however, the same interval was used for every measurement.

Forearm blood flow was measured by venous occlusion plethysmography with a temperature-compensated mercuryin-rubber strain gauge. A wrist cuff occlusion pressure of $200 \mathrm{~mm}$. Hg was used with a collecting cuff pressure of 50 $\mathrm{mm}$. Hg. Flows were recorded for 10 seconds in each 15 seconds, and each value shown is the mean of 10 measurements.

Blood pressure was measured by sphygmomanometer. In experiments in which central venous pressure was recorded a long nylon catheter was introduced into an arm vein and advanced to a central position; it was then connected to a Statham $23 \mathrm{D}$ pressure transducer. The zero level for venous pressure was taken as mid-chest.

Ergotamine was given as the tartrate and ergometrine as the maleate; the weights of the drugs refer to the salts.

Experiments were carried out in six normal volunteers. The studies were performed with the subjects lying comfortably on a bed, and they were allowed to rest for at least half an hour before any measurements were made. An intravenous infusion was set up in the arm not being used for measurements and an infusion of $0.9 \%$ saline was maintained by a constant-rate syringe driver throughout the experiment. A minimum of three control measurements of venous compliance were obtained, and forearm blood flow and arterial pressure were recorded. The saline infusion syringe was then changed for one containing the ergot alkaloid under study in solution in saline, and a total of $0.25 \mathrm{mg}$. was given over 10 minutes. Five further measurements of venous compliance were made at 10 -minute intervals beginning 10 minutes after completion of the infusion, and when ergometrine was being studied an additional measurement was made immediately the drug had been given. Forearm blood flow and arterial pressure were recorded 20 and $\mathbf{4 0}$ minutes after the infusion had been completed.

In one study with every subject saline was infused for 10 minutes after the control measurements and a further two measurements were obtained at 10-minute intervals before the alkaloid was infused. The fact that the alkaloid was not being given during the first infusion was known' to the experimenters when they acted as subjects, but was not known to the other volunteers. In one subject the forearm venous compliance was recorded at 10-minute intervals over a period of one and a half hours without administration of any drug.

Statistical comparisons were made by Student's $t$ test as adapted for use with paired data.

\section{Results}

Effect of Saline (Six Subjects).-The average of the two control measurements of venous compliance was $1.74 \mathrm{ml} . / 100$ $\mathrm{ml} . / 25-5 \mathrm{~mm}$. $\mathrm{Hg}$. $\neq$ while the average at 10 and 20 minutes after infusion of saline was $1.68 \mathrm{ml} . / 100 \mathrm{ml}$. (Table I).

TABLE I.-Effect of Saline on Forearm Venous Compliance and Forearm Blood Flow. Results are Shown as the Mean \pm 1 Standard Deviation

\begin{tabular}{|c|c|c|}
\hline & $\begin{array}{l}\text { Venous Compliance } \\
(\mathrm{ml} . / 100 \mathrm{ml} . / 25-5 \mathrm{~mm} . \mathrm{Hg})\end{array}$ & $\begin{array}{l}\text { Forearm Blood Flow } \\
(\mathrm{ml} . / 100 \mathrm{ml} .)\end{array}$ \\
\hline $\begin{array}{l}\text { Control } 1 . . \\
\text { Control } 2 . . \\
10 \text { minutes after saline } \\
20 \text { minutes after saline }\end{array}$ & $\begin{array}{l}1.72 \pm 0.31 \\
1.76 \pm 0 \cdot 27 \\
1.67 \pm 0 \cdot 41 \\
1.69 \pm 0.37\end{array}$ & $\begin{array}{l}2 \cdot 2 \pm 0 \cdot 6 \\
2 \cdot 1 \pm 0 \cdot 8\end{array}$ \\
\hline
\end{tabular}

The changes are not statistically significant.

Forearm blood flow averaged $2.2 \mathrm{ml} . / 100 \mathrm{ml}$. before saline and $2.1 \mathrm{ml} . / 100 \mathrm{ml}$. after.

Effect of Repeated Measurement of Venous Compliance (One Subject).-In the subject in whom venous compliance was measured at 10-minute intervals for one and a half hours the values obtained showed little variation and the level had only a slight tendency to fall with time (Fig. 1).

Effect of Ergotamine (Five Subjects).-In every subject there was a large fall in forearm venous compliance after ergotamine (Table II and Fig. 1). This change was already well

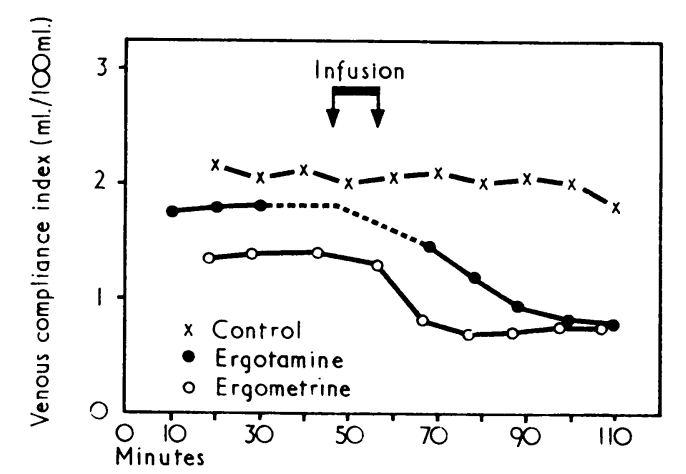

FIG. 1.-Effect on forearm venous compliance of ergotamine tartrate and ergometrine maleate in one subject. The drugs were infused intravenously in a dose of $0.25 \mathrm{mg}$. over the time shown; in the control study no infusion was given. The pressure interval used for measurement of venous compliance varied slightly from study to study.

developed at 10 minutes, but the maximum . effect was not attained until 40 minutes, at which time the decrease in compliance amounted to $49 \%$ on average. When compared with the immediately preceding control measurements, the fall in venous compliance was highly significant at each interval. Forearm blood flow increased by $14 \%$ on average at 20 minutes, but had returned to the control value by 40 minutes; the changes were inconsistent, however, and the increase at 20 minutes was not statistically significant. Calculated mean arterial pressure increased by $14 \%$ at 20 minutes and $17 \%$ at 40

‡ In some subjects the pressure interval used differed slightly from the standard limits of $25-5 \mathrm{~mm}$. $\mathrm{Hg}$, but the same interval was used for all measurements in any one experiment. 
minutes; these changes have not been analysed statistically since the measurements were not obtained by direct recording.

Effect of Ergometrine (Five Subjects).-Forearm venous compliance showed a large fall in every subject after ergometrine. A significant reduction in compliance was already apparent at the completion of the infusion and reached its maximum by 40 minutes, when it amounted to $41 \%$ on average (Table II). The change from the control values was oped more slowly than that to ergometrine (Fig. 1). Ten minutes after the completion of the infusion, only $48 \%$ of the eventual response had occurred on average with ergotamine, whereas $77 \%$ had occurred with ergometrine; this difference was highly significant $(\mathrm{P}<0.01)$.

Effect on Central Venous Pressure (Two Subjects).-In one subject the central venous pressure was measured together with the forearm venous compliance before and after ergot-

TABLE II.-Effect of Ergotamine and Ergometrine on Forearm Venous Compliance, Forearm Blood Flow, and Calculated Mean Arterial Pressure. Results are shown as the Mean \pm 1 Standard Deviation

\begin{tabular}{|c|c|c|c|c|c|c|}
\hline & \multicolumn{3}{|c|}{ Ergotamine (five subjects) } & \multicolumn{3}{|c|}{ Ergometrine (five subjects) } \\
\hline & $\begin{array}{c}\text { Venous Compliance } \\
(\mathrm{ml} . / 100 \mathrm{ml} . / 25-5 \mathrm{~mm} . \mathrm{Hg}) \\
\end{array}$ & $\begin{array}{c}\text { Forearm Blood } \\
\text { Flow (ml./100 ml.) }\end{array}$ & $\begin{array}{c}\text { Mean Arterial } \\
\text { Pressure (mm. Hg) }\end{array}$ & $\begin{array}{c}\text { Venous Compliance } \\
(\mathrm{ml} . / 100 \mathrm{ml} . / 25-5 \mathrm{~mm} . \mathrm{Hg})\end{array}$ & $\begin{array}{c}\text { Forearm Blood } \\
\text { Flow (ml./100 ml.) }\end{array}$ & $\begin{array}{c}\text { Mean Arterial } \\
\text { Pressure (mm. Hg) }\end{array}$ \\
\hline \multirow{3}{*}{$\begin{array}{l}\text { Control } 1 \\
\text { Control } 2 \\
\text { Immediately after drug } \\
10 \text { minutes after drug } \\
20 \text { minutes after drug } \\
30 \text { minutes after drug } \\
40 \text { minutes after drug } \\
50 \text { minutes after drug }\end{array}$} & $\begin{array}{l}1 \cdot 68 \pm 0.39 \\
1 \cdot 71 \pm 0.30\end{array}$ & $2 \cdot 2 \pm 0 \cdot 6$ & & \multirow{3}{*}{$\begin{array}{l}1.90 \pm 0.38 \\
1.84 \pm 0.46 \\
1.52 \pm 0.45 \\
1.24 \pm 0.40 \\
1.12 \pm 0.46 \\
1.12 \pm 0.48 \\
1.10 \pm 0.41 \\
1.15 \pm 0.45\end{array}$} & $1.9 \pm 0.8$ & \\
\hline & $\begin{array}{l}1.31 \pm 0.26 \\
1.04 \pm 0.25 \\
0.93 \pm 0.24\end{array}$ & $2.5 \pm 0.5$ & $96 \pm 5$ & & $2 \cdot 2 \pm 1 \cdot 1$ & $88 \pm 10$ \\
\hline & $\begin{array}{l}0.86 \pm 0.22 \\
0.86 \pm 0.23\end{array}$ & $2 \cdot 2 \pm 0.5$ & $98 \pm 7$ & & $1.9 \pm 0.7$ & $86 \pm 8$ \\
\hline
\end{tabular}

The fall in venous compliance following administration of the drugs is significant at the $1 \%$ level for all measurements except that immediately following ergometrine The fall in venous compliance following administration of the drugs is significant at the $1 \%$ level
whificant at the $5 \%$ level. The changes in forearm blood flow are not statistically significant.

significant at each interval. Forearm blood flow tended to increase in some subjects, but the average change for the whole group, which was an increase of $16 \%$ at 20 minutes and a return to the control level at $\mathbf{4 0}$ minutes, was not significant. The calculated mean blood pressure increased by $9 \%$ at 20 minutes and by $6 \%$ at $\mathbf{4 0}$ minutes.

Comparison of Speed of Action of Ergotamine and Ergometrine.-The venoconstrictor response to ergotamine devel-

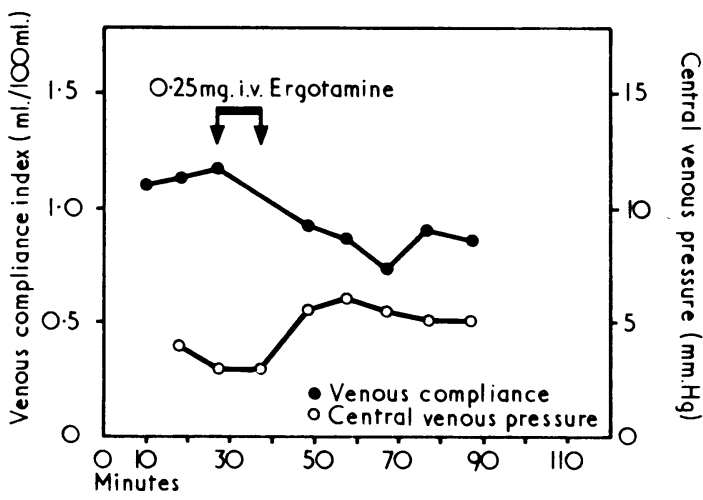

FIg. 2.-Effect of ergotamine tartrate $(0.25 \mathrm{mg}$. intravenously) on venous compliance and central venous pressure.

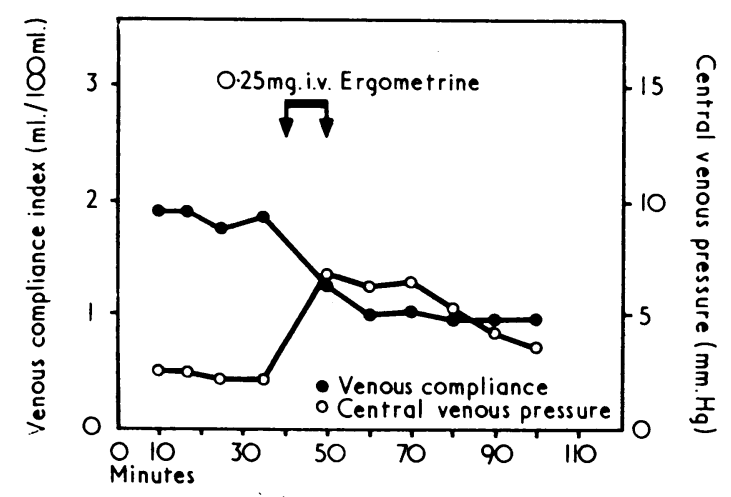

Fig. 3.-Effect of ergometrine maleate $(0.25 \mathrm{mg}$. intravenousiy) on venous compliance and central venous pressure. amine, and in another before and after ergometrine. In both subjects the decrease in venous compliance was accompanied by a clear increase in central venous pressure, which amounted to $4.2 \mathrm{~mm}$. $\mathrm{Hg}$ after ergotamine and $3 \mathrm{~mm}$. $\mathrm{Hg}$ after ergometrine (Figs. 2 and 3 ).

\section{Discussion}

For many years it has been known that the natural ergot alkaloids exert a direct constrictor effect on the arterial system (Dale, 1906; Rothlin, 1947; Bluntschli and Goetz, 1948; Barcroft et al., 1951). The present study indicates that ergotamine and ergometrine also have a potent constrictor effect on the forearm veins in man when given in doses that are in the lower range of those used clinically. It is of interest that there was a clear difference in speed of action between the two drugs, the venoconstriction after ergometrine appearing much more rapidly than that after ergotamine; a similar difference in speed of action is seen in the effect of the two alkaloids on the uterus (Smith, 1938). Several earlier observations are consistent with the occurrence of venoconstriction after ergot preparations. Thus Dale (1906) noted a fall in the leg volume of a cat when an extract of ergot was given; Freis et al. (1949) found a decrease of vascular distensibility in the extremities in man after dihydroergocornine; and Lands et al., (1950) recorded a large reduction of leg volume in the dog after intraarterial ergotoxine. It does not appear to have been appreciated, however, that these changes might reflect an action of the alkaloids on the veins in addition to the arteries. In the present investigation only ergotamine and ergometrine were studied, but it seems probable that their venoconstrictor action will be found to be shared by other alkaloids of the group.

Our experiments have been limited to the forearm, but it is likely that the constrictor response affects a significant proportion of the systemic venous bed, since the central venous pressure rose substantially in the two subjects in whom it was measured. A rise in venous pressure, as measured in the antecubital fossa, has been noted after ergometrine (Brown et al., 1947), and those workers suggested that it might result in part from a decreased capacity of the vascular reservoir. A rise in venous pressure in an antecubital vein was also observed by Freis et al. (1949) after dihydroergocornine, but it was thought to be caused by increased arterial flow.

The demonstration of the potent constrictor effect of ergot- 
amine and ergometrine on the veins suggests that a fall in the compliance of the systemic venous reservoir may be an important component of the circulatory changes that follow the administration of clinical doses of these alkaloids. This action may also be an important factor in the production of certain of the harmful side-effects that are occasionally observed. The aggravation of angina pectoris that sometimes follows the administration of ergotamine has been assumed to result from coronary arterial spasm, but there is no evidence to confirm this view. The constrictor action on the veins could provide an alternative explanation: the rise in central venous pressure that results will tend to increase the size of the heart and so augment the metabolic needs of the left ventricle, and this change would be expected to facilitate the development of angina pectoris in response to exercise or other stress. It is interesting to note that the circulatory actions of ergotamine are almost exactly the reverse of those of the organic nitrates which probably relieve angina partly as a result of the venodilatation that they produce.

The occasional occurrence of pulmonary oedema in women with mitral stenosis who have been given ergometrine immediately after delivery is usually attributed to a sudden transfusion of blood resulting from the powerful uterine contraction. Brown et al. (1947), however, who suggested this mechanism, also put forward the idea that a decreased capacity of the vascular reservoir might play a part. The finding that ergometrine induces a rapid constriction of the forearm veins provides strong support for this view, and the resulting rise in central venous pressure may well be an important factor in the precipitation of pulmonary oedema in patients with impaired cardiac function.

The potent effect of ergotamine and ergometrine on the veins should be considered whenever these drugs are used clinically. The venoconstriction that they produce is haemodynamically equivalent to the administration of a rapid blood transfusion, and this should be borne in mind before either alkaloid is given to a patient who has a cardiac disorder.

\section{REFERENCES}

Barcroft, H., Konzett, H., and Swan, H. J. C. (1951). fournal of Physio$\log y, 112,273$.

Barnes, C. G. (1965). Medical Disorders in Obstetric Practice, 2nd ed. Oxford, Blackwell.

Bluntschli, H. J., and Goetz, R. H. (1948). American Heart fournal, 35, 873.

Brown, E., Sampson, J. J., Wheeler, E. O., Gundelfinger, B. F., and Giansiracusa, J. E. (1947). American Heart fournal, 34, 311

Dale, H. H. (1906). Fournal of Physiology, 34, 163.

Freis, E. D., et al. (1949). Fournal of Clinical Investigation, 28, 1387.

Friedman, A. P., Von Storch, T. J. C., and Araki, S. (1959). New York State fournal of Medicine, $59,2359$.

Goodman, L. S., and Gilman, A. (editors) (1965). The Pharmacological Basis of Therapeutics, 3rd ed. New York, Macmillan

Lands, A. M., Luduena, F. P., Grant, J. I., Ananenko, E., and Tainter, M. L. (1950). Fournal of Pharmacology and Experimental Therapeutics, 100, 284 .

Robinson, B. F., and Wilson, A. G. (1968). Clinical Science, 35, 143.

Rothlin, E. (1947). Bulletin der Schweizerischen Akademie der medizinischen Wissenschaften, 2, 249.

Smith, R. G. (1938). Fournal of the American Medical Association, 111, 2201 .
Cummary: Specific pathogen-free domestic cats were fed with tissue cysts containing Toxoplasma gondii. In two infected cats large numbers of oocysts were produced in the faeces; no oocysts were observed in the faeces of the uninfected control cat. Five days after the feeding of the toxoplasms profuse schizogonic and gametogonic stages were observed in the epithelial cells of the small intestine of one infected cat. A single schizont was observed in an intestinal epithelial cell of a second cat six days after being fed the tissue cysts. There was no evidence of schizogony or gametogony in the uninfected control cat. The stages observed in the intestinal epithelium are identical with those of the well-known endogenous cycles of coccidian parasites. The appearance of these stages, together with the nature of the oocyst, indicates that $T$. gondii is a coccidian parasite closely related to the genus Isospora.

\section{Introduction}

Toxoplasma gondii is probably the last protozoan parasite of medical importance whose life cycle has yet to be elucidated. Much information has been compiled on its epidemiology,

\footnotetext{
* Senior Lecturer, Department of Biology, University of Strathclyde, Glasgow C.1. † Research Fellow, Department of Biology, University of Strathclyde,
Glasgow C.1.

$\ddagger$ Director, Department of Toxoplasmosis and Viral Diseases, Statens Seruminstitut, Copenhagen.

$\$$ Physician, Department of Toxoplasmosis and Viral Diseases, Statens Seruminstitut, Copenhagen.
}

pathology, immunology, serology, and other aspects of its effect on the life of man and other animals, but it is only relatively recently that a clearer understanding of its life history and transmission has emerged. It was thought that the elucidation of its natural transmission mechanism would provide a clue to the life cycle. This has indeed been proved to be the case.

Research on transmission of toxoplasmosis employing cats was initiated by Hutchison (1965). He showed that a resistant form of Toxoplasma could be transmitted in the faeces of cats which had been fed with chronically infected toxoplasmic carcases. Hutchison (1967) put forward the hypothesis that this resistant form of Toxoplasma was transmitted within nematode ova, but subsequent work by ourselves and others has cast doubts on the validity of this hypothesis (Jacobs, 1967; Dubey, 1968; Hutchison et al., 1968; Frenkel et al., 1969, Hutchison and Work, 1969a; Sheffield and Melton, 1969; Work and Hutchison, 1969a).

It was next shown by Work and Hutchison (1969a, 1970b) that the infective unit passed in cat faeces was a cyst. Moreover, they pointed out that this cyst showed remarkable similarities to the coccidian oocyst of Isospora (Hutchison and Wor'x, 1969b; Work and Hutchison, 1969b). In the absence of evidence of schizogony and gametogony, however, they tentatively called their cyst "the new cyst" rather than an oocyst. Siim et al. (1969), using coccidian terminology, showed that within the oocyst there were two sporocysts each containing four sporozoites, thus strengthening the hypothesis that $T$. gondii is related to the genus Isospora. The purpose of 